\title{
UNDERSTANDING THE CURRENT DISCOURSE OF REHABILITATION: WITH REFERENCE TO DISABILITY MODELS AND REHABILITATION POLICIES FOR EVALUATION RESEARCH IN THE SOUTH AFRICAN SETTING
}

\begin{abstract}
Evaluation of rehabilitation programmes is essential in order to monitor its effectiveness and relevance. There is however a need to consider policies when conducting evaluation research in rehabilitation. The aim of this paper is to present the theoretical and legislative underpinnings of rehabilitation in South Africa. A narrative review of national and international disability legislation and empirical research in context of rehabilitation was conducted. The findings of this review reveals that as a fluid construct, the discourse of rehabilitation has been underpinned by the changing theoretical and socio-political understandings of disability. This in turn has influenced various international and national health and disability policies and legislations that oversee the implementation of rehabilitation practice. Despite this, there has been little evaluation of public health rehabilitation services in context of these policies and legislations in South Africa. The fluidity of rehabilitation need to be considered when conducting evaluation research in rehabilitation.

\section{Mji G1, Chappell P1, Statham S², Mlenzana $\mathrm{N}^{3}$, Goliath $\mathrm{C}^{4}$, DeWet $\mathrm{C}^{5}$ and Rhoda $\mathrm{A}^{3}$}

KEY WORDS: REHABILITATION, NATIONAL REHABILITATION POLICY, EVALUATION, SOUTH AFRICA

\section{INTRODUCTION}

Globally, according to the World Health Organisation's (WHO) World Report on Disability (WHO 2011), more than 1 billion people live with some form of disability. Within South Africa, current estimates for the number of people with disabilities converge at five to six percent of the population, equating to around 2.5 million people (Stats SA 2001). It should be noted that information obtained in

\section{Correspondence Author:}

Gubela Mji

Centre for Rehabilitation Studies,

Stellenbosch University

South Africa

Email: Gumji@sun.ac.za the 2011 Census is not comparable with previous data as the definition of disability used in the 2011 census was different to what was previously used. The definition of disability used in the 2011 census yielded information relating to the type and degree of disability and not overall percentage. According to the 2011 census report however, $>90 \%$ of people reported having "no difficulty or limitation preventing them from carrying out certain functions..." (Stats SA 2011:46).

People with disabilities face various physical and attitudinal barriers to participation in their communities and access to vital health services (WHO, 2011). These barriers, have led to national and international legislative changes being brought into force in order to strengthen the rights of people with disabilities. The current guiding policies in South Africa are the National Rehabilitation Policy (NRP) of South Africa (DOH, 2000), the UN Convention for the Rights of Persons with Disabilities (UNCRPD) (UN, 2011) and the WHO Community Based Rehabilitation (CBR) Guidelines (WHO, 2010). All of these policies and guidelines set out the objectives for effective and accountable rehabilitation services that include the full participation of people with disabilities in the planning, monitoring and evaluation of services. The aim of this paper is to present an overview of the theoretical and legislative underpinnings of rehabilitation in South Africa 
in order to inform research related to the evaluation of research.

\section{THE PANOPTIC GAZE OF HEALTH PROFESSIONALS AND REHABILITA- TION SERVICES}

The discourse of rehabilitation is not a fixed entity, but is rather a fluid construct that has been subject to the changing theoretical and socio-political understandings surrounding disability. For instance, historically, in South Africa rehabilitation provision within public health services have predominantly been institutionally based and focused on individual therapy rendered within a medical model approach (Rule, Lorenzo, Wolmarans 2006, OSDP 1997). Within this medical model approach, the bodies of disabled people were perceived as incomplete and in need of professionals who were presumed to have the knowledge and ability to define and provide for the disabled body. As depicted by Crawford (1994, p.1352), the [disabled] body was seen as 'a composite of technical operations and functional capacities and provided the advice of experts is followed it is possible to alter the individual for the better'. Given this perspective, the objective of the medical model was to eliminate or return impaired bodies to societal normativity (Simmons, Blackmore \& Bayloss, 2008). In this light, rehabilitation has been defined as 'a process aimed at enabling people with disabilities to reach and maintain their optimal functional levels by providing them with the tools they need to attain independence and self-determination' (WHO, 2007).

In placing the discourse of rehabilitation within a Foucauldian analysis, the supervisory approach of the medical model symbolises the application of what Tremain defines as 'modern panopticism', whereby the lives of people with disabilities are within constant surveillance by health professionals (Treman 2005, p.84). Within this context, it would appear that the notion of power is firmly in the hands of health professionals whilst people with disabilities ultimately play a passive role. However, as highlighted by Michel Foucault (1978, p.94), power is 'not something acquired, seized, or shared... it is exercised from innumerable points'. In view of this, just like rehabilitation, power is also a fluid entity and everyone has the potential to exercise power. Foucault (1978, p.95) also goes on to suggest that 'where there is power, there is resistance'.

This notion of resistance generated a new kind of counter-politics. For instance, within the context of disability and rehabilitation, the rise of the disability rights movement and a social model of disability, saw the development of resistance towards the normative measures of the medical model. For example, during the late 1980s in South Africa people with disabilities began to rise up and challenge rehabilitation professionals to work with the disability rights movement. According to Chappell and Johannsmeier (2009), one of the main criticisms of the medical model approach is that it places sole responsibility for change upon the individual and pays little attention to the barriers that hinder the full social integration of people with disabilities. These barriers can either be physical (e.g. inaccessible buildings, transport, lack of sign language interpreters etc.) or attitudinal (e.g. discrimination in the workplace).

\section{SOCIAL CONSTRUCTION OF REHA- BILITATION}

The social model of disability therefore brought about a paradigm shift in how disability is constructed (Rule, 2006). In this instance, a distinction is made between impairment and disability. As outlined by Albert (2004) and Barnes and Mercer (2005), disability is not only about health and pathology, but about discrimination and social exclusion, which is often imposed on individuals with impairments. Therefore, although not denying the need for medical intervention, the social model acknowledges disability as a civil rights issue. Additionally, it also advocates for the intercollaboration of both political and civil society organisations such as health, social development, labour and education in raising the profile of people with disabilities in the disabled people struggle against discrimination and for social inclusion (Albert 2004; Bury 2005).

Bury (2005), asserts that Disabled People Organisations (DPOs) should also be recognised as key actors in civil society. In doing so they are able to conduct dialogue and lobby political and social structures for the needs of people with disabilities in collaboration with other organisations. People with disabilities are no longer perceived as passive role players. In addition, it also outlines the fluidity of power and the rejection of people with disabilities as an invisible group to one able to develop new definitions and political form (Shakespeare 1996). In reviewing the socio-political stance taken by the social model, it can clearly be seen that there is a shift in responsibility from the individual to society.

Placing this in context of the discourse of rehabilitation, more focus is now given to intervening in the environment in an attempt to facilitate the full integration of people with disabilities into local communities (Chappell \& Johannsmeier 2009; Barnes \& Mercer 2005). Quintessentially, it is not so much the individual who needs rehabilitation, but rather the social and physical structures that disadvantage people with disabilities. Furthermore, in recognising the key role of DPOs, the social model calls for rehabilitation professionals to revise their practice and share their skills with people with disabilities (Wirzand Chalker, 2002). In doing so rehabilitation professionals need to also recognise and respect the experiences and expertise of people with disabilities themselves.

The social model is mainly focused on removing barriers, some have questioned whether using this approach would ignore the 'real rehabilitation' needs of people with disabilities such as mobility and other comprehensive health needs and special education (Thomas \& Thomas 2002). What's more, disability feminists have argued that the social model ignores the personal experiences of people with disabilities, which include issues surrounding the body such as impairment, sexuality and pain (Hughes \& Patterson 1997).

Discourses surrounding the dualism between impairment and disability have 
caused a major shift in the conceptualisation of rehabilitation. In recognition of this change, the International Classification of Functioning, Disability and Health (ICF) has been developed as a way of understanding the complex interaction between features of the biological, psychological, cultural and social factors of disability (WHO, 2001). In this model, which is also known as the biopsychosocial model, disability is defined as the outcome of the interaction between a person's health condition and the context in which the person finds themselves (Scheneider 2006). This context includes external environmental factors (e.g. assistive devices, physical accessibility, societal attitudes), and those factors internal to the person (e.g. age, sex, coping skills, personality). As elements of the body and personal and external environmental factors change, so the outcome will also change.

\section{INTERNATIONAL AND NATIONAL LEGISLATION THAT IMPACT ON REHABILITATION SERVICES}

Rehabilitation services are subject to several national and international policies. The reforms of 1994 in South Africa and the creation of the UN Millennium Development Goals in 2000 have necessitated adjustments of existing health policies and the development of new ones. The overarching aim was to improve access to health services especially to the poor and previously disadvantaged communities. The rise of the disability rights movement and the social model has played an influential role in the enhancement of disability legislation and a call for change in the structure and implementation of rehabilitation services. In South Africa for example, the outset of the Integrated National Disability Strategy (which was based on the UN Standard Rules for the equalisation of opportunities for persons with disabilities (UN Standard Rules 1994) shaped the foundation for the National Rehabilitation Policy (DOH 2000). This is clearly evident within the goal of the NRP, which stipulates that:

'...this policy is to improve accessibility to all rehabilitation services in order to facilitate the realisation of every citizen's constitutional right to have access to health care services. This policy should also serve as a vehicle to bring about equalisation of opportunities and to enhance human rights for persons with disabilities, thereby addressing issues of poverty and disparate socio-economic circumstances (DOH 2000, p.2)

In analysing the objectives of the NRP critically, it can clearly be seen that it is resolutely based on the strategy of CBR, whereby people with disabilities should play a very active role in the planning, implementation and evaluation of rehabilitation services. However, although the NRP was adopted in 2001, there is no empirical evidence to suggest that rehabilitation services have been implemented according to the objectives of the NRP.

Another recent disability legislation that influences the delivery of rehabilitation is the UN Convention for the Rights of Persons with Disabilities (2006), which South Africa ratified and brought into law in 2007. Based on the UN Standard Rules (1994), the Convention aims to ensure all rights and freedoms for all people with disabilities are respected and protected (Rule et al 2006). Although many of the fifty articles set out in the UNCRPD (2006) relate indirectly to the discourse of rehabilitation, five of the articles, as depicted in Table 1, strongly feature rehabilitation.

These articles give clear guidelines regarding how to respond to the rehabilitation needs of people with disabilities. What's more, these articles resonate with the objectives outlined in the NRP of South Africa.

Table 1: Selected Articles on rehabilitation from UN Convention for the Rights of Persons with Disabilities

\begin{tabular}{|c|c|}
\hline Article No. & Topic Area \\
\hline 9 & Accessibility \\
\hline 19 & $\begin{array}{r}\text { Living independently and being } \\
\text { included in the community }\end{array}$ \\
\hline 20 & Personal mobility \\
\hline 25 & Health \\
\hline 26 & Habilitation and rehabilitation \\
\hline
\end{tabular}


Table 2: CBR Matrix (WHO 2010)

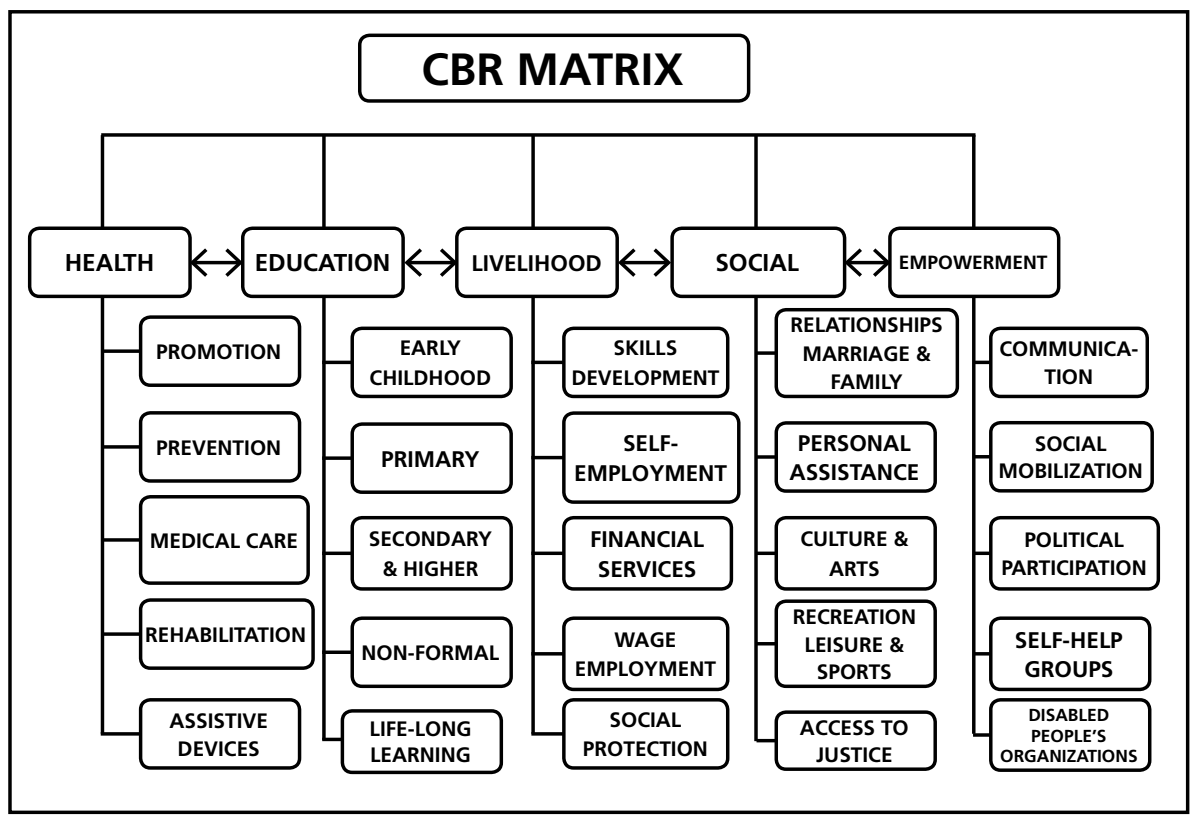

Table 3: Principles of CBR (WHO 2010)

\begin{tabular}{|c|c|}
\hline CBR PRINCIPLES & DEFINITION \\
\hline Participation & $\begin{array}{r}\text { Active contribution of people with disabilities } \\
\text { in CBR practice and monitoring }\end{array}$ \\
\hline Inclusion & $\begin{array}{r}\text { Placing people with disabilities and their issues } \\
\text { in the mainstream }\end{array}$ \\
\hline Sustainability & $\begin{array}{c}\text { Benefits of the programme must be lasting beyond } \\
\text { life of programme }\end{array}$ \\
\hline Self-advocacy & $\begin{array}{c}\text { Consistent involvement of service users in terms of } \\
\text { defining practice \& indicators }\end{array}$ \\
\hline
\end{tabular}

rehabilitation (CBR) framework. CBR has emerged as an effective strategy of providing rehabilitation services to people with disabilities and their families (Chappell and Johannsmeier 2009). According to Finkenflugel and Rule (2008), CBR takes an inclusive development approach, which means that rehabilitation services should include people with disabilities in key mainstream development programmes and strategies. Within the NRP, the strategy of CBR has been described as an approach to delivering service and not necessarily the service itself (DoH 2000).

As CBR is part of community development, one of its key components is the reduction of poverty amongst people with disabilities. This focus coincides with other global initiatives that aim to address development and poverty such as The Millennium Development Goals (2000). Coleridge (2006) articulates that one of the first steps in tackling poverty is to give a voice and full participation to those most affected by poverty. Recognising disability as a rights-based issue and focusing on the concept of equalisation of opportunities provides the CBR strategy with an appropriate platform in which to address poverty alleviation.

In accordance with the CBR Guidelines (WHO, 2010), the strategy of CBR is composed of five topic areas, which are health, education, livelihoods, social and empowerment. As depicted in Table 2, each of these topic areas have five key elements, which inform the implementation of CBR. According to the CBR Guidelines (WHO 2010), programmes may not necessarily address all elements in the matrix, but only address some of the topic areas and its elements depending on local circumstances.

According to Bury (2005), there are a number of community-orientated rehabilitation programmes that claim to be a CBR programme. One such approach is the use of outreach. Bury (2005, p.42) describes outreach as "programmes run by health care workers at a local level to provide complex professional care which directly addresses patients' pathology, impairments and / or disabilities'. As denoted by Rule et al (2006) CBR is a process of empowerment in which people with disabilities and their communities participate in a process that leads to decisions by and for themselves. Building on this premise, the whole strategy of CBR is underpinned by the CBR principles of participation, inclusion, sustainability and self-advocacy as illustrated in Table 3 .

In analysing the principles of CBR, it's clear to see how they coincide with both the UNCRPD (UN 2006) and the objectives of the NRP (DOH, 2000). Quintessentially, given the notion put forward by the NRP (DOH, 2000, p.6) that CBR is an 'approach' to service delivery, the principles of CBR (as described in Table 3) should therefore be applied to all levels of rehabilitation to ensure they are in alignment with both the NRP and UNCRPD.

\section{EVALUATION OF REHABILITATION SERVICES}

Evaluation of rehabilitation programmes is essential in order to monitor its effectiveness and relevance. This is reiterated within the objectives of the NRP (DOH, 2000) and in Article 31 of the UNCRPD (UN, 2006). Hartley (2002) also articulates that without evaluation the impact of rehabilitation is not confirmed, which in turn could affect the sustainability of a programme. To help guide the evaluation of rehabilitation programmes, Jonsson (cited in Mannan \& Turnball, 2007) and Velema and Cornielje (2003) make a distinction between two evaluation 
models, which are individual and programme evaluations.

Through reviewing the literature, it appears that the majority of rehabilitation evaluations tend to use an individual model and have a tendency to focus on changes in activities of daily living (ADL), quality of life and vocational abilities of people with disabilities. For instance, Lagerkvist (2003) conducted an evaluation study of two CBR programmes in the Philippines and Zimbabwe. Through taking case histories and testing ADL ability amongst 206 people with disabilities it was found that there was a $78 \%$ 93\% gain in abilities following CBR intervention. Likewise, in using structured interviews with 77 people with disabilities in Botswana, LundgrenLindquist and Nordholm (1999) found most people had maintained high levels of independence in ADL. Furthermore, $20 \%$ of adults were working as a result of rehabilitation intervention.

Although the individual evaluation model provides knowledge on the effectiveness of professionally-driven rehabilitation intervention, there is no indication of the levels of participation or self-advocacy achieved by people with disabilities in the service given the principles of $\mathrm{CBR}$ as mentioned earlier. The uses of programme evaluations however, are more wide-ranging and involve overall aspects such as efficiency, relevance, impact and sustainability of a programme (Mannan \& Turnball 2007). In addition, Velema and Cornielje (2003, p.1252) suggest that programme evaluations should also address environmental issues such as the extent to which the programme is a learning organisation, the 'resources available to people with disabilities, the inclusiveness of education and employment and a number of ecosocial variables e.g. housing, sanitation, transport etc'. In reviewing the literature, of the few studies that used programme evaluation, most of them were CBR evaluations. For example, Sharma and Deepak (2001) used a participatory approach to evaluate a CBR programme in North Central Vietnam. In using a SWOT Analysis (strengths, weaknesses, opportunities and threats), they carried out six focus groups and eleven semi-structured interviews with people with disabilities and a few CBR workers.

Within context of South Africa, a national audit on disability research found that there was very little empirical evidence that has evaluated rehabilitation services (McLaren et al, 2006). Of those that have been completed, they have mostly focused on CBR programmes, in particular the role of CBR Workers. For example, Concha (2001) completed an evaluation study, which looked at the value of CBR Workers on people with disabilities living in rural communities in Limpopo. Using a mixed-method design, the study examined the number and types of clients seen by the CBR Workers, their effectiveness and the perceptions of the CBR Workers regarding the value of their work. A similar study conducted by Chappell and Johannsmeier (2009) also used a mixed-method design to evaluate the impact of Community Rehabilitation Facilitators (CRFs) working in six of the provinces in South Africa. The study highlighted both the impact and gaps in CRFs work with people with disabilities, their families, groups and communities.

In relation to evaluation of rehabilitation within institutions, it was found that although some studies evaluated the impact of interventions on people with disabilities (Kahonde et al, 2010) or improvements in quality of life (Jelsma, 2007); very few have actually evaluated the attitude or structure of public health rehabilitation services. In addition, there is also a lack of empirical evidence that has explored how institutional rehabilitation services have either included people with disabilities in evaluating services or how the services have placed issues of disability in the mainstream. This lack of evidence may coincide with Koutzky and Tollman's (2008) previous analysis that healthcare in South Africa still resides in a medical model approach whereby people with disabilities still play a passive role.

Rehabilitation is thus seen as a matter of situated and lived interaction of people with their social and physical environment. Hence, according to Schwandt (2003, p.94) evaluation must 'not be cast in exclusively instrumentalist terms, but rather continuously try and grasp the lived reality by being with or in relation to the activities one evaluates'.

\section{CONCLUSION}

The discourse of rehabilitation is both a complex and fluid entity that has been subject not only to the changing theoretical underpinnings of disability theory, but also international and national policy and legislation. This has in turn influenced various international and national health and disability policies such as the NRP that oversee the implementation of rehabilitation practice. Despite this, there has been little evaluation of public health rehabilitation services in the context of these policies and legislations in South Africa. This review highlights the need for recognising the fluidity of rehabilitation during evaluation research. It suggests that rehabilitation as a fluid construct has to respond to the changing sociopolitical discourse that impacts on the lives of disabled people.

\section{ACKNOWLEDGEMENTS}

Project funder: The South Africa Netherlands Research Programme on Alternatives for Development (SANPAD)

Members of the research team: Handri Liebenberg, Rochelle Felix, Conran Joseph, Anne Kumurenzi, Maatje Kloppers and Siphokazi Gcaza.

Research advisors: Professor Marietjie Devilliers, Mr Huib Corneljie, Professor Arnie Eide, Ms Blanche Pretorius and Ms Catherine Collingwood.

\section{REFERENCES}

Albert B 2004. The social model of disability, human rights and development. Disability Knowledge and Research. Electronic Citation. http://www.handicap-international.fr/bibliographiehandicap/1Handicap/ModelesComprehension/socialModel.pdf. Last accessed March 2012

Barnes C, Mercer G 2005 Understanding impairment and disability: towards an international perspective. In Barnes, C. \& Mercer, G. (Eds.) The Social Model of Disability and the Majority World. University Press, Leeds 
Bury T 2005 Primary Health Care and community based rehabilitation: implications for physical therapy. Asia Pacific Disability Rehabilitation Journal 16 (2): 29-61

Chappell P, Johannsmeier C 2009 The impact of CBR as implemented by Community

Rehabilitation Facilitators on people with disabilities, their families and communities in South Africa. Disability and Rehabilitation Journal 31(1): 7-18

Crawford R 1994 The boundaries of the self and the unhealthy other: reflections on health, culture and AIDS. Social Science and Medicine; 38 (10): 1347-1365

Coleridge P 2006 CBR as part of Community Development and Poverty Reduction. In Hartley S Editor. CBR as part of community development: A poverty reduction strategy. London: University College London, Centre for International Child Health

Concha M 2009 The value of the serviced offered by the Community Rehabilitation Worker. South African Journal of Occupational Therapy. 39(2): 10-18.

Finkenflugel H, Rule S 2008 Integrating community-based rehabilitation and leprosy rehabilitation services into an inclusive development approach. Leprosy Review 79: 83-91

Foucault, M. The history of sexuality Vol. 1: An introduction, trans. Robert Hurley, Harmondsworth: Penguin; 1978

Hartley S CBR 2002 A participatory strategy in Africa. London: University College London

Hughes B, Patterson K 2007 The social model of disability and the disappearing body: Towards a sociology of impairment. Disability and Society; 1997, 12 (3): 325-340

Jelsma, J. The determinants of health-related quality of life in urban and rural isi-Xhosa speaking people with disabilities. International Journal of Rehabilitation Research; 30 (2): 119-126

Kahonde CK, Mlenzana N, Rhoda 2010 A Persons with physical disabilities' experiences of rehabilitation services at Community Health Centres in Cape Town. SA Journal of Physiotherapy; 66 (2): $1-6$

Kautzky K, Tollman S 2008 A perspective on Primary Health Care in South Africa. In Health Systems Trust. Editors. South African Health Review; Health Systems Trust: Durban

Lagerkvist B 1992 Community-based rehabilitation- outcome for the disabled in the Philippines and Zimbabwe. Disability and Rehabilitation; 14 (1): $44-50$
Lundgren-Lindquist B, Nordholm LA 1999 Community-based rehabilitation in Moshupu village, Botswana. Disability and Rehabilitation; 21: $10-1$

Mannan H, Turnball AP 2007A review of community based rehabilitation evaluations: quality of life as an outcome measure for future evaluations Asia Pacific Disability Rehabilitation Journal;18 (1): 29-45

McLaren P, Philpott S, Chappell P, Roberts A 2006 A national audit of disability research undertaken in South Africa 1994 - 2005. Unpublished Report. Department of Social Development; Pretoria

Republic of South Africa. Department of Health 2007 Comprehensive service plan for the implementation of Healthcare Internet.. Electronic Citation. www.westerncape.gov.za/Text/2007/7/ may15,2007-csp_2.pdf. Last accessed March 2012

Republic of South Africa, Department of Health 2000 Rehabilitation for all: National Rehabilitation Policy. Pretoria: Government Printers;

Office of the Status of Disabled People 1997 Integrated National Disability Strategy: White Paper; Government Printers: Pretoria Republic of South Africa.

Rule S, Lorenzo T, Wolmarans M 2006 Community Based Rehabilitation: new challenges. In Watermeyer, B. et al, Editor. Disability and social change: a South African agenda. HSRC: Cape Town

Shakespeare T 1996 Disability, identity and difference. In Barnes, C. and Mercer, G. Editors. Exploring the divide. The Disability Press; Leeds

Schneider M 2006 Disability and the environment In B. Watermeyer et al. Editors. Disability and social change: a South African agenda, Cape Town: HSRC;

Schwandt T 2003 Notes on Evaluating the Ecology of Rehabilitation Praxis. Scandinavian Journal of Disability Research; 5 (1): 93-105

Sharma M, Deepak S 2001 A participatory evaluation of community-based rehabilitation programme in North Central Vietnam. Disability and Rehabilitation; 23 (8): 352-358

Simmons B. Blackmore T, Bayliss P 2008 Postmodern synergistic knowledge creation: extending the boundaries of disability studies. Disability and Society, 23 (7): 733-745

Statictics South Africa (Stats SA) 2011Census in Brief. Internet. Electronic Citation http://www. statssa.gov.za.Accessed April 2013

Statistics South Africa (Stats SA) 2001 Census in Brief. Internet. Electronic Citation http://www. statssa.gov.za. Last accessed March 2012
Thomas M, Thomas MJ 2002 Some controversies in community based rehabilitation. In Hartley, S. Editors. CBR: A participatory strategy in Africa. London: University College London

Tremain S 2005 Foucault and the government of disability. Michigan: University of Michigan Press

United Nations 2006 Convention on the Rights of Persons with Disabilities Internet. Electronic Citation www.un.org/esa/socdev/enable/rights/ convtexte.htm. Last accessed October 2011

United Nations. Millennium Development Goals 2000 Internet. Electronic Citation. www.un.org/ millennium/declaration/ares552e.htm. Last accessed October, 2011

United Nations. Standard Rules for the Equalisation of Opportunities for Persons with Disabilities 1994. UN Press: New York

Velema J, Cornilje H 2003 Reflect before you act: providing structure to the evaluation of rehabilitation programmes. Disability and Rehabilitation 25 (22): 1252-1264

Wirz S, Chalker P 2002 Training issues in Community Based Rehabilitation in South Asia. Asia Pacific Disability Rehabilitation Journal; Series 2, January: 111-127

World Health Organisation 2011 World report on disability. WHO Press: Geneva

World Health Organisation 2001 International Classification of Functioning, Disability and Health. Internet. Electronic Citation.

World Health Organisation 2010 Community Based Rehabilitation Guidelines. WHO Press: Geneva

World Health Organisation 2007 Health Topics. Internet. Electronic Citation. http://www.who.int/ topics/rehabilitation/en/. Last accessed February 2012 